\title{
La existencia, entre el ser y la nada
}

\section{Existence, between being and nothingness}

\author{
ALEJANDRO ROJAS JIMÉNEZ \\ Universidad de Málaga
}

Recibido: 21/03/2017 Aceptado: 22/03/2017

\begin{abstract}
RESUMEN
En este trabajo se analiza en primer lugar la noción de existencia en la metafísica de Aristóteles, para comentar posteriormente su transformación tras la aparición «moderna» de la «nada» (que se analizará sobretodo en el caso concreto del idealismo crítico de Kant), para reflexionar posteriormente, siguiendo la lectura de Heidegger, sobre el papel «fundamentador» de la nada para la posibilidad de una nueva metafísica, después del idealismo, bajo la forma de un realismo «trascendental» capaz de «abandonar» la intencionalidad fenomenológica para abrirse a un ámbito que no es ya el del noema y lo conocido, sino el de la existencia real.
\end{abstract}

\section{PALABRAS CLAVES}

EXISTENCIA, SER, NADA, REALIDAD, METAFÍSICA

\begin{abstract}
In this paper, (i.), I analyze the notion of existence in the Metaphysics of Aristotle, (ii.) I comment on its transformation after the «modern» appearance of «nothing» (which will be analyzed above all in the concrete case of Kant's critical idealism). (iii.) I reflect, following the reading of Heidegger, on the «foundational» role of nothingness for the possibility of a new metaphysics, after idealism, in the form of a «transcendental» realism capable of «abandoning» the phenomenological intentionality to open itself to an area that is no longer that of the noema and the known, but that of real existence.
\end{abstract}

KEYWORDS

EXISTENCE, BEING, NOTHING, REALITY, METAPHYSICS

(C) Contrastes. Revista Internacional de Filosofia, vol. XXII-N² (2017), pp. 203-215. ISSN: 1136-4076

Departamento de Filosofía, Universidad de Málaga, Facultad de Filosofía y Letras Campus de Teatinos, E-29071 Málaga (España) 


\section{LA DISTINCIÓN ARISTOTÉLICA ENTRE «LO QUE LA COSA ES» \\ Y «EL HECHO DE QUE SEA».}

Aristóteles, en los ANALÍtiCOS POSTERIORES, distingue expresamente entre «qué sea algo»y el hecho de «que algo sea». ${ }^{1}$ Una cosa es conocer qué sea algo y otra cosa distinta percatarse de la existencia de ese algo. Este «saber que ese algo es» es una auténtica intelección de su estar siendo realmente. Lo podríamos expresar con Zubiri: una aprehensión de su realidad como tal. Para entender esto bien, en su debido contexto histórico, debemos hacer valer cierta y necesaria «intuición hermenéutica» ${ }^{2}$, y no apresurarnos a leer estos pasajes teniendo en la cabeza, al menos de momento, posteriores ampliaciones de esta cuestión; como es el caso por ejemplo de la distintio realis tomista.

Los famosos ejemplos que Aristóteles propone en los Analíticos posteriores para pensar este «que algo sea» son, entre otros, el tronar y el destellar. Se trata pues de advertir la diferencia entre saber qué es el tronar y su tronar mismo, qué sea el destellar de la estrella y el destellar mismo. En esta línea, su párrafo más famoso es desde luego aquel de la Metafísica ${ }^{3}$ donde el «que algo sea» se corresponde con «tu ser blanco», o - como traduce Heidegger«tu-ser-ante-nosotros-como-blanco». ${ }^{4}$ La traducción alemana podría arrojar algo de luz cuando distingue entre Was y Dass. Concretamente traduce aquel «el qué sea» por das wesentliche Was (el qué esencial), y el «que sea» por das Dass (el que) ${ }^{5}$. Este «el que» no debe verterse sin más por existencia, porque existencia es un término que ha sido pensado de muchas maneras en distintos sistemas filosóficos, y que, en consecuencia, ha sido dicho de muchas maneras. Teniendo a Aristóteles cerca conviene andar precavidos de esta pluralidad de decires ${ }^{6}$ cuanto más después del paso de la historia.

1 Cfr., Analytica posteriora 93a, 8, 17-20, y 92b, 11-12.

2 El término que utiliza Heidegger, y que podríamos considerar que contradistingue del de «intuición artística» (NF 1870, 7[159]) de Nietzsche y el «intuición intelectual» de Schelling (Allgemeine Übersicht, AA I,4, 128/SW I, 401), y que propone como alternativa al de evidencia en Husserl, es el de «intuición hermenéutica» (Zur Bestimung de Philosophie, en GA 56/57, p. 72).

3 «desde luego, tú no eres blanco porque sea verdadero nuestro juicio de que tú eres blanco, al contrario, porque tú eres blanco, nosotros decimos algo verdadero al afirmarlo» Metaph. IX 10, 1051b 6-9

4 GA 38, p. 175.

5 Organon, en la edición de Holzinger de 2013 para Berliner Ausgabe, y que incorpora la traducción de Kirchmann para Zweite Analytiken oder: Lehre von Erkennen en Meiner, Leipzig 1877 que aquí reproduczo: «Denn wie man das Warum sucht, nachdem man das Dass erkannt hat und wie mitunter Beides zugleich offenbar wird, aber niemals das Warum vor dem Dass erkannt werden kann, so kann auch offenbar das wesentliche Was nicht ohne das Dass erkannt werden; denn man kann unmöglich das Was eines Gegenstandes kennen, wenn man nicht weiss, $o b$ er ist.»

6 Cfr., Met. 1003a21-b19. 
Podríamos decir que esa existencia está pensada como el -lo diré así- su «ser-de-hecho», pues lo que designa fundamentalmente es su «estar ahí delante de hecho». Se trata del ente en tanto que ahí delante. Que el ente en tanto que visto, en tanto que oído, y a fin de cuentas en tanto descubierto, está en cualquier caso «de hecho» ahí delante: tratamos con cosas que existen, que están ahí realmente delante.

Aristóteles distingue entre «concebir» y «afirmar» para sentenciar que no puede haber error (ni verdad) en decir lo que se concibe como se concibe. ${ }^{7}$ Si lo ves blanco lo ves blanco. Si el zumo te sabe mal te sabe mal. Si tienes frío tienes frío. Y es así, haga calor, sea chocolate, o seas negro. Pues bien, ocurre además que en ese verte negro, además, te inteligo como realmente ahí delante. $\mathrm{O}$ dicho de otra manera: en acto. Este estar ahí delante es el punto de partida desde el que se puede entender bien la actitud metafísica que nacería de la conciencia de dos tipos de acto: enérgeia y entelécheia. ${ }^{8}$

Esta distinción está expresada muy clara por Aristóteles en el De Ani$m a$ : «el sujeto sensible es en potencia tal como es en entelecheia el objeto sensible» ${ }^{9}$. Es decir: el ser, ese que es advertido (o intelegido) como realmente ahí delante, antes de ser conocido es el ser que puede ser conocido. Pero ese ser que puede ser conocido ya está siendo. Insiste, también en el De Anima, «todas las cosas nacen de lo que ya es en entelecheia». ${ }^{10}$ Las cosas ya existen pues en acto antes de ser conocidas. Aristóteles «supone» pues un acto previo a la actualidad ${ }^{11}$ o dicho de otra manera: $\langle\text { intelige }\rangle^{12}$ que hay una realidad ya antes de ser percibida. De lo contrario tendríamos que decir con Berkeley que «esse est percipi (aut percipere).»" ${ }^{13}$

Aristóteles no puede preguntarse en términos modernos qué sea ese ser antes de su presentificación. Debe de ser lo mismo, corresponderse con lo presente, sólo que no estando presente. Debe tratarse pues de lo «ausente». Muy pertinente resulta aquí recordar la traducción heideggeriana de aletheia como un desocultar que, por cierto, no tiene lugar primeramente con la actividad teórica,

7 Met. IX, 10.

8 Para un estudio detenido: La doctrina del acto en Aristóteles op. cit.

9 De Anima, 418a 3-6.

10 De Anima, 431a 3.

11 L. Polo, El Ser, I, Eunsa, Pamplona, 1966, p.140.

12 Se podría desde luego construir desde este punto toda una teoría del conocimiento para precisar qué tipo de intelección se está llevando aquí a cabo. Yo me limitaré a hablar, como mínimo, de una intuición intelectual. Pero un análisis mucho más profundo al respecto debe buscarse en L. Polo, Teoría del conocimiento, 5 volúmenes, Eunsa, Pamplona, 1984ss.

13 Cfr., Principles I, 1-6. 
sino, como dice en el Informe Natorp, con la vida práctica. Ya en el Sofista había sido concluyente en este sentido al pensar la aletheia desde la frónesis. ${ }^{14}$ La cuestión para un filósofo moderno no es sin embargo tanto de ausencia como de vacío. Este tipo de ideas, o de conceptos (en este caso el de ser en su sentido extramental) están vacíos por carecer del contenido aportado por la intuición sensible. Y ante el vacío, ante su abismo, conviene retroceder y no precipitarse. Kant será explícito: lo oportuno es «domar» ${ }^{15}$ a la razón, contenerla, y así evitar este tipo de preguntas, haciendo ver que la «idea» de ese ser no percibido es sólo eso: una idea de la razón.

\section{El SENTIDO DE La REALITÄT EN Kant.}

Realidad, para Kant, significa sólo: serle dado al sujeto. ${ }^{16}$ Lo que está diciendo Kant no es otra cosa, por recuperar el lenguaje que hemos usado al principio de este trabajo, que nos es dado un «que» que convertimos en «qué». De ese «que» sin embargo sólo acertamos a inteligir su Realität en el sentido anteriormente recogido, y por eso Kant, en lugar de hablar de un acto anterior a su actualidad, hablará en su lugar de cómo la razón no tiene más remedio que pensarlo como existente. Para Kant esa realidad es en realidad una realidad pensada, supuesta. Ningún nombre parece convenirle pues más que el que el propio Kant le dió: noumenon. Para Kant estamos, diciéndolo con la terminología tradicional, ante una distinctio rationis.

Para Aristóteles esa existencia era sin embargo real. Es de hecho tan real que su teoría del conocimiento está montada sobre la consideración de que al conocer lo que conocemos es lo que se corresponde con eso que realmente está ahí de hecho. Para evitar confusiones, mucho más acertado me parece sentenciar que Kant y Aristóteles no hablan de lo mismo porque ha cambiado el sentido en el que ambos conciben, utilizaré la expresión aristotélica, «la naturaleza del ente». ${ }^{17}$

14 M. Heidegger, Platon: Sophistes, GA 19, p. 52.

15 "Da bedarf sie so sehr einer Disciplin, die ihren Hang zur Erweiterung über die engen Grenzen möglicher Erfahrung bändige und sie von Ausschweifung und Irrthum abhalte". $K r V$, B 739

$16 \mathrm{KrV}, \mathrm{B} 272 / \mathrm{A} 225$

17 Met., VII, 1. 
Para Aristóteles la naturaleza es principio de movimiento ${ }^{18}$. Y ello, entendido de tal manera que siendo así es «la esencia de los seres». ${ }^{19}$ Kant no puede continuar a Aristóteles en esta línea porque cuando Kant se pone a filosofar ya no existe esta naturaleza. Que ésta no existe es lo que enuncia Cotes en su famoso prólogo a la segunda edición de libro de Newton cuando dice que la ley de la inercia «es una ley de la naturaleza asumida por todos», ya que esta lex inertiae de Newton, en contra de la tesis fundamental aristotélica, dice que todo cuerpo persiste en su estado de reposo o de movimiento rectilíneo uniforme si no es obligado a cambiar de estado por fuerzas inculcadas. $\mathrm{O}$ lo que es lo mismo: que el principio del movimiento no debe buscarse en la naturaleza de los cuerpos. Si el principio del movimiento no debe buscarse en la naturaleza de los cuerpos, la «filosofía de la naturaleza» debía ser sustituida. Con Kant esta sustitución llega a su culminación (el famoso «giro copernicano» ${ }^{20}$ ) cuando paralelamente a lo que ocurre con la «física» resuelve que para entender porqué el mundo llega a ser el mundo que es cuando lo entendemos tampoco debemos buscar las explicaciones en la naturaleza.

La pregunta acerca de qué sean las cosas en un mundo desnaturalizado (donde espacio y tiempo son intuiciones), es una pregunta bien distinta a la pregunta acerca de qué sean las cosas antes de ser conocidas cuando estas «cosas» están siendo pensadas como entes «naturales». ${ }^{21}$ Sin naturaleza, las cosas de las que habla Kant son, en sí mismas, nada. Han sido vaciadas de contenido. Un contenido que es lo que para Aristóteles justamente había que entender.

La filosofía de Kant es, bien visto, una respuesta a la pregunta metafísica enunciada en su lugar por Leibniz: ¿porque el ser y no más bien la nada? Lo podríamos decir con un lenguaje algo más cercano: ¿por qué fenómenos? Esta pregunta no tiene sentido para Aristóteles: el ser es. Pero para Kant el ser es sólo una idea (noúmeno). Lo que es, es el fenómeno que en sí mismo consiste en un aparecer, en un llegar a ser desde la nada. Esa nada, ante la que Kant

18 «Las cosas que existen naturalmente, tiene todas en sí el principio del movimiento o del reposo, unas el del movimiento en el espacio, otras el del crecimiento y de perecimiento, otras el del cambio. Por lo contrario, una litera, un traje, todas las cosas de este género, todo lo que es producto del arte no tiene en sí el principio de su cambio, y por esta causa estos objetos son de piedra, de tierra, o una mezcla de estos elementos; y esta causa accidental es para ellos el principio del movimiento y del reposo. La naturaleza es un principio, una causa que imprime el movimiento y el reposo, causa inherente a la esencia misma del objeto, no causa accidental.» Phys. II, 1.

19 «Se sigue de todo lo que precede, que la naturaleza primera, la naturaleza propiamente dicha, es la esencia de los seres, que tienen en sí y por sí mismos el principio de su movimiento» Met, V, 4, 1013b-1025a.

$20 C f r ., K r V$ B XVI-XVII.

21 Cfr., Phys., II,1. 
retrocede, es esquivada cuando nos mantenemos dentro de los límites del entendimiento, o lo que es lo mismo, dentro de los límites de los fenómenos. Pero entonces las cosas han dejado de ser Gegenstände para ser objetos. Las cosas, entendidas como Gegenstände son las que están ahí delante (entgegen-stehen) en un sentido propiamente aristotélico. El objeto, sin embargo, es un producto, un resultado que se entiende con relación a un sujeto.

Pero esto significa que en la cosa, para Kant y a diferencia de Aristóteles, está la huella de la nada. Lo podríamos decir de este modo: para Kant, en la cosa (Ding) está ya implícito lo incondicionado (Unbedingten). Eso incondicionado es la nada, la diferencia. Pero no es una nada que no haga nada: sin ser, actúa, ejerce cierta acción productiva que nos afecta, nos llega a través de las intuiciones sensibles y es entonces, sólo entonces, cuando el entendimiento puede hacerse cargo de esa nada y darle forma al fenómeno.

Este punto es determinante: ante esa nada cabe retroceder. Es lo que hizo Kant. Pero también lo más lógico, y por ello lo que hacen Carnap, y la filosofía analítica en general. Ante la nada mejor es retroceder porque de ella no se puede decir nada; que diríamos parafraseando oportunamente a Wittgenstein. Pero la nada sigue estando ahí, la pregunta de porqué el ser y no la nada no se desvanece cuando simplemente se la desconsidera.

\section{EL PENSAR ANTE LA NADA.}

En 1928, concretamente el 24 de julio, Heidegger se hizo cargo del discurso inaugural del curso en la Universidad de Friburgo. La lección tiene un título bastante curioso: ¿Qué es metafísica? Digo que es curioso porque Heidegger no tenía la intención de exponer lo que hace o de lo que habla la metafísica, como quizás cabría esperar de un título semejante. No tenía intención de hablar sobre los temas de los que se ocupa la metafísica. Su interés se centraba más bien en lo que él considera que es la cuestión fundamental de la metafísica (su Grundfrage ${ }^{22}$ ), y que enuncia del siguiente modo: ¿por qué es en general el ente y no más bien la nada?

Decíamos que la diferencia entre la concepción kantiana y aristotélica de la filosofía era la entrada en escena de la nada. Una nada que entra en escena, decía, ejerciendo un «acto» concreto al que Heidegger da un nombre que es conocido por todos: la nada, dice Heidegger, nichtet. Conviene no traducir apresuradamente este nichtet, sino demorarnos un poco.

a) Las tres traducciones del nichten.

Son muchos los que ante la pregunta por la nada se quedan anodadados. La nada, lo diré en primer lugar siguiendo la primigenia traducción de X. Zu- 
biri a la famosa proposición heideggeriana, anonada ${ }^{23}$. Algunas declaraciones personales acerca de este anonadamiento han llegado a ser muy conocidas y exitosas. Es el caso por ejemplo de M. Bunge, quien ha confesado que para él una expresión semejante no dice nada. La nada anonada cuando nos enfrentamos a ella tomándonos en serio que la nada no es nada. Si fuera algo bastaría decir lo que es y en lo que consiste su ser. Pero la nada no es un ente, no es algo que está siendo. Si acaso, lo diré siguiendo en esta ocasión la traducción de A. Leyte y H. Cortés, más que ser desiste; la nada desiste. Pero no desiste porque no llegue a ser. Lo que con desistir quieren designar estos autores es más bien «una suspensión inherente del ser mismo». ${ }^{24}$

Hay una diferencia esencial entre la propuesta de Leyte-Cortés y la propuesta de Bunge, para los primeros la proposición tiene sentido, para el segundo no lo tiene. Y como no lo tiene para el filósofo uruguayo, incapaz de reconocer su estupefacción ante la pregunta misma, opta por ridiculizar aquella expresión que él no traduce como «anonada» ni «desiste», sino, siguiendo la tercera propuesta clásica de traducción al castellano: la nada «nadea». ${ }^{25}$

Comprender el sentido de ese «nadear», requiere sin embargo que intentemos pensar etimológicamente el propio proceso de construcción del neologismo «nichten».

Anodadar, que es la propuesta de traducción de X. Xubiri, se dice en alemán en realidad vernichten. Ocurre también que el prefijo ver tiene un sentido negativo que se puede observar en otros términos como verbieten, que traduciríamos como prohibir. Por eso, cuando se elimina ese prefijo se elimina el sentido negativo y se obtiene un nuevo sentido. Se ve bien en el siguiente ejemplo: «prohibir» se convierte en «ofrecer» cuando en lugar de verbieten decimos bieten. Cabe pensar que lo mismo ocurra con «nichten» ${ }^{26}$, y que por ello no tengamos que pensarlo a partir del nicht, sino a partir de vernichten, si es que nichten es el resultado de haber eliminado el prefijo «ver» en «vernichten». El éxito de la traducción de Xubiri pasa en parte por entender que tal es la procedencia etimológica del término, y no tanto por conservar el juego de palabras; que es lo que llevó a A. Leyte y H. Cortés ha desistir de ella y anularla. Esta clave etimológica puede ampliarse con el estudio al respecto de Heinz y Schluck en su Die Philosophie Martin Heideggers. ${ }^{27}$

23 Was ist Metaphysik?, GA 9, 116.

$24 C f r$. la anotación a la traducción de M. Heidegger, «Carta sobre el humanismo», en M. Hediegger, Hitos, Alianza, Madrid, 2007, p. 293, n. 54.

25 Cfr., M. Bunge, La relación entre la sociología y la filosofía, Ensayo, Madrid, 2001, p. 313.

26 Cfr., Kar-Heinz Volkmann-Schluck, Die Philosophie Martin Heideggers, Königshausen und Neumann, Würzburg, p. 110.

27 Cfr., Ibid. 
La traducción de Xubiri es mucho más profunda de lo que parece. Yo creo que merece la meta que la retengamos, porque en español -y a diferencia del alemán- anonadar tiene tanto el sentido negativo como el positivo. Quiero decir, vale tanto para traducir vernichten como para traducir nichten. Anodadar en sentido negativo es reducir a la nada, aniquilar, nihilizar. No es de eso de lo que se trata. En su sentido positivo, por el contrario, es verse desconcertado. La nada, lo diré así, desconcierta. Pero desconcertar es impreciso, porque puede ser entendido aún en sentido negativo: como un quedarse perplejo. Es el sentido que encontramos en Kant. Kant no se refiere directamente a la nada, pero sí indirectamente, pues se refiere a todas esas cuestiones que se nos revelan faltas de respuesta. Una perplejidad, pues, en la que cae la razón humana sin culpa, dice en el prólogo a la Crítica de la razón pura, al verse acosada por cuestiones que no puede ni apartar ni contestar.

La nada no se puede entender. Y llegados aquí debemos mencionar necesariamente a R. Carnap. La posición de Carnap, aunque no lo pueda parecer al principio, es bien distinta de la de Bunge. Carnap no dice que sea mera palabrería, sino que se produce un uso indebido del lenguaje. Y Carnap tiene razón. Creo que entender bien la proposición heideggeriana pasa por entender su falta de sentido. Dirá Carnap que podemos decir der Regen regnet ${ }^{28}$ pero, puesto que la nada no es nada, no se puede decir das Nicht nichtet, sino más bien que «no hay nada» en expresiones del tipo: es gibt kein $x$, das draussen ist. La proposición no tiene sentido. Si entender, como creo, la proposición heideggerianamente pasa por sacar a la luz esa falta de sentido que con acierto pone de manifiesto Carnap, y que con desacierto ridiculiza Bunge, entonces no nos puede valer a pesar de todo «anonadar». Es preciso crear un neologismo.

b) Naufragando en la etimología.

Sobre la nada no se puede hacer ciencia porque no hay aquí nada que entender. No hay nada que entender aquí, porque la nada es nada, o como diríamos en español: la nada no es nada. ¿Y por qué íbamos a pensar en algo que no es nada? ¿Cómo puede surgir la pregunta por la nada? Porque a pesar de todo tenemos experiencia de la nada, diría Heidegger, en la angustia. No se puede hablar de la nada sin remitir a la angustia. Uno se angustia ante la nada cuando pone en cuestión el ser, porque al preguntarnos por el ser (no por el ente, sino por el ser del ente) nos descubrimos intentando responder a una pregunta ¿y por qué no más bien la nada?

Esta pregunta abruma. Abrumar no paraliza como el estupor o la perplejidad. Molesta y agobia, pero no deja perplejos ni estupefactos. Ante la

28 Cfr., R. Carnap, «La superación de la metafísica mediante el análisis lógico del lenguaje», en A. Ayer, El positivismo lógico, FCE, México, 1963. 
perplejidad sólo cabe, o así lo parece al menos en un primer momento, la opción de Carnap. Pero lo que nos abruma no nos deja estupefactos, sino que nos da qué pensar. Bien entendido que pensar está siendo pensado aquí como respuesta a una demanda que se impone como tarea. ${ }^{29}$ Este imponerse como demanda es en realidad la versión heideggeriana (e histórica) de aquel «verse acosada por cuestiones que no puede apartar ni contestar» que decía Kant en el prólogo a la Crítica de la razón pura. La nada puede angustiar, anodadar, agobiar, molestar: ese es el efecto que padecemos al entrar en contacto con la pregunta por la nada. Existe un verbo en español que recoge al mismo tiempo estos tres sentidos de abrumar, molestar y agobiar; aunque es hoy en día un uso poco frecuente. De sus cuatro sentidos, el cuarto según la RAE. Dicho término provendría del término latino enecare, construído desde necare, que significa «dar muerte sin provocamiento de sangre». Se derivaría a su vez de nex (muerte, distinguiéndose de mors, moris) y caedes. Es por ello la muerte que se produce cuando nos ahogamos en el agua. De aquí procede el español «anegar». La angustia ante la nada es semejante a la angustia del náufrago, incluso a la angustia «sublime» y romántica de El caminante entre las Nubes ante una inmensidad indeterminada que anega y nos ahoga. La nada inhunda, anega, y de ahí la angustia. Dos caminos a partir de aquí: o paramos y vamos para otro lado (Carnap) o saltamos al abismo.

La anda anega, a pesar de todo, no parece convincente como traducción, porque no respeta el juego de palabras. Algo parecido ocurre si trabajamos con el término inundar. Si a inundar le quitamos el «in» repitiendo el proceso creador de Heidegger al eliminar el «ver» nos queda: la nada hunde. La nada nos hunde. Al inundarnos no nos ahogamos. No aniquila, sino que del desconcierto de la nada se puede salir, como se sale del fondo del mar: nadando. Nadar es, aquí, escapar de la nada. Sólo es necesario escapar de la nada cuando la nada nos inunda. Y por eso lo que hace la nada es provocar el nado. La nada inunda sin ahogar, hace que todo esté nadando (a la deriva) en la nada misma. Y sin embargo la nada de Heidegger lo que hace es más bien hacer que nazca ese ámbito que nos ahoga y nos hunde. Ese ámbito no es nada, y sin embargo ese ámbito surge. Pero inundar no puede ser entonces el término que buscamos. Tiene que estar relacionado más bien con «nacer».

Quiero llamar la atención de que nuestra «nada» en castellano no viene de «no», como ocurre en alemán, sino de nata (de natus-a-um). Y yo quiero aprovechar esto para decir que lo que nace es la cuestión que nos inunda. En latín se dice res nata para designar el asunto en cuestión. Y aquí el asunto en cuestión es «lo que da que pensar». Lo que da que pensar no es algo, una cosa,

29 Cfr., M. Heidegger, Was heisst denken. G 55, p. 189. 
sino lo que no puede ser reducido a una cosa. La nada nadea efectivamente, como dice Bunge, pero cuando nadear no procede de nihil sino de nata.

Debería decir pues que la nada nadea es la mejor opción de traducción, pero no puedo decirlo ya hoy. A las traducciones a veces les pasa que no valen para siempre. Ocurre, como mi buen amigo P. Chamizo suele hacer notar a propósito de la traducción al inglés de la Fenomenología del Espíritu de Hegel, que dejó de valer Mind, debido a la connotación que este término había llegado a tener con los nuevos estudios de la mente. Algo parecido ocurre con «nadea». Valía antes, hasta Bunge y los que la han convertido en un sin sentido. Es preciso buscar un término nuevo que le devuelva el sentido, que la vuelva a emparentar con «nacer», para que la expresión vuelva a designar «algo que da que pensar» en lugar de un sin sentido. Ante la proposición de la nada heideggeriana debemos situarnos como ante el cuadro negro de Malévich. No podemos decir que no haya nada pintado, aún cuando se trate de un cuadro negro donde no hay nada que ver. ${ }^{30}$ La nada tiene que ver con el sentido, o mejor, con la falta de sentido. Cuando no hay nada que entender, ¿por qué seguir pensando? Pues sólo hay una solución: que sea la «ausencia», lo que no hay, la nada, lo que funda la tarea de seguir pensando.

c) Saliendo del naufragio: la nada «ennadece».

Cuando tenemos que tomar una decisión vital buscamos llenarnos de razones, y necesitamos llenarnos de razones porque ese tipo de decisiones no se resuelven fácilmente, y no se resuelven fácilmente porque a menudo la duda no es entre una decisión buena o mala, sino entre dos opciones que se nos revelan igualmente racionales y lógicas. Pero hay que decidirse por una. Y entonces, la lógica no resuelve el problema, tampoco la verdad. Habremos de seguir pensando, buscando razones que nos hagan decantarnos, lo que no necesariamente pasa por entender la otra opción como menos lógica o menos racional. Porque no hay una opción, porque no hay un camino, porque depende de «nuestras» razones, nos podemos angustiar ante ese abismo, ante esa nada. Esa nada no es simplemente una ausencia, sino una ausencia que nos afecta y nos obliga a pensar desde la angustia. La nada hace algo que nos ahoga, que nos hunde, y nos obliga a salir a nado a la superficie (que no a la tierra, al suelo firme en el que promete desembocar la salida de la caverna).

Cicerón usa la expresión «pro re nata» con el sentido de «según las circunstancias». Todavía hoy en EEUU se puede leer en el prospecto de un fármaco las abreviaturas p.r.n, que aluden a ese «pro re nata», con el sentido de según vaya surgiendo. Esto, referido a un fármaco debe ser interpretado como «si persiste

30 Aunque las últimas noticias avisaban de que con infrarrojos es posible ver dos negros jugando en una cueva. 
el dolor». La nada no tiene que ver con desistir como decíamos al principio, sino con persistir. Volviendo a lo que decíamos en el párrafo anterior: lo que persiste es eso que hace que sigamos teniendo que pensar. La nada, mientras persiste, mientras no se puede reducir su ausencia a una respuesta o a una idea, sigue dando que pensar. En este sentido es como el ser, cuando se diferencia del ente.

La nada crece hasta anodadar, crece abrumando. Es justamente lo contrario de ennudecer, que significa dejar de crecer. ¿No cabría acaso la posibilidad de crear un neologismo a partir de ennudecer, pero para decir justamente lo contrario (como hace nichten a partir del vernichten)? Diremos entonces que «ennadece», bien entendido que la nada del «ennadece» no está emparentada etimológicamente con el «no», sino con el «nata» de «nacida», desde donde procede etimológicamente nuestra nada en español.

No hay pues surgir algo que comparece, sino que ella misma es la que «surge», creciendo ante nosotros hasta ahogarnos en ella y provocar el nado. La nada, detrás del ser, amenaza con destruir toda seguridad y toda certeza, todo lo sólido; amenaza con aniquilarlo todo, pero no aniquila (no es vernichten), sino que en el surgimiento de esa amenaza, y sólo en la medida en que nos ahoga y angustia, «crece lo salvador»: la tarea del pensar meditativo y sereno -diríamos con el Heidegger de la Gelassenheit. El pensar se mantiene vivo sólo gracias a la nada que ennadece.

\section{SIN «NADA» QUE SE OPONGA, LA RAZÓN LO ABARCA TODO.}

Entender correctamente el idealismo alemán, tiene que ver, pienso yo, justamente con tomar conciencia de que cuando la tarea del pensar se funda en la ausencia de término, la razón lo puede abarcar todo. Si no lo vio Kant fue porque no quiso. Schelling y Fichte pronto se dieron cuenta de esto. Cuando Heidegger, según mi propuesta de interpretación de aquel nichten (y quiero agradecer la discusión al respecto con A. Ciria y R. Caballero ${ }^{31}$ ) dice que la nada da que pensar, esto tiene que ser entendido asumiendo la tesis de Carnap de que no hay nada que entender.

Pero esto tiene una lectura que me parece bien interesante remarcar. Cuando Heidegger cree fundamentar la metafísica, en realidad, lo que está fundamentando es el idealismo. Y mucho me temo que no cualquier idealismo, sino el alemán. Un realista, en el fondo, podría haber quedado anodadado hace ya varios parágrafos. Si bien, existen realismos con remanente idealista. Por ejemplo, el «realismo crítico inmediato», que se distinguiría del «realismo crítico mediato» de Mercier, acepta una relación inmediata entre el pensamiento y la realidad trascendente. El representante principal de esta tesis sea quizás

31 Discusión pública llevada a cabo en el foro para la promoción de la filosofía y la cultura, que promueve la asociación FICUM. 
Noël. Noël influyó como es conocido en Zubiri, quien propone una fenomenología «objetivista» que me parece interesante resaltar frente a Heidegger y el idealismo alemán.

Ser realistas después del idealismo, que sería volver de algún modo a Grecia, debe hacerse aceptando por un lado que el ser (al igual que la conciencia) no tiene sustantividad (no es la entelequia aristótelica) y que sin embargo, como sí decía Aristóteles, sigue siendo lo primero, lo fundamental. El realismo crítico diríamos que es el realismo que surge de aunar estas dos premisas fundamentales, y sin embargo, y como creo que con acierto acusa Gilson, el realismo crítico es idealista; una continuación del idealismo crítico de Kant. Podríamos mencionar por ejemplo el realismo crítico de Popper, para quien la realidad no se puede conocer, salvo de una manera aproximada. El realismo de Zubiri, sin embargo es plenamente realista cuando afirma que la realidad se puede conocer, pero al mismo tiempo es trascendental, porque conocer la realidad como realidad no es en Zubiri reducirla a una entelequia. Yo creo que podríamos denominar a su realismo como «realismo trascendental», porque le ocurre como al realismo «virtual» que se lee en la teoría del conocimiento de Polo. ${ }^{32}$ En ninguno de estos casos estamos ante realismos ingenuos, ni ante realismos idealistas, como el crítico. Lo que hacen estos dos filósofos realistas españoles es romper con la intencionalidad de la conciencia que parecía incuestionable después de Husserl.

Dice Zubiri: «el nóema y la nóesis no son momentos intelectivos primarios. Lo radical es un devenir de actualidad, un devenir que no es noético ni noemático, sino noérgico.»" ${ }^{33}$ «Noérgia» es un neologismo creado por Zubiri, como explica D. de Molina, «a partir de nous (entendimiento, inteligencia) y ergón (acto, creación, obra), para subrayar el carácter físico y real de la inteligencia como fundamento de su carácter noético o meramente representacional.» ${ }^{34}$ Este neologismo le permite hablar de una realidad actualizada en la inteligencia. Antes de dicha actualización la realidad no ha sido aún entificada, pero la intelección la afirma como ya siendo ${ }^{35}$, «in esendo» ${ }^{36}$ antes de su «presentificación». No siendo por ello nada de ente, o siendo nada de ente. Volvemos pues a la nada. Desde el realismo trascendental o virtual parece que se produce por un lado una afirmación de la realidad que sólo es posible por el «ennadecimiento» de la nada. Ella es la que lo provoca, la que exige la actuación del nous para salir de las ideas y razones del logos y la dianoia. La nada, la que no procede

32 Cfr., J. García, Principio sin continuación, SPICUM, Málaga, 1998.

33 X. Zubiri, Inteligencia y Realidad, Alianza, Madrid, 1980, p.64.

34 D. Molina, «Realidad y ser: una lectura comparada de Zubiri y Heidegger», Thémata 36 (2006), 153-69, p. 155, n. 5.

35 Cfr., Inteligencia y realidad op. cit., p. 225.

36 X. Zubiri., El Hombre y Dios, Alianza, Madrid, 1986, p. 54. 
etimológicamente del «no» (no la nada del Nichts), sino la que proviene de nata y desde la que habíamos construido el neologismo «ennadecer» debe ser pensada real, principio que despierta al nous, que lo saca de su embelesamiento en sus construcciones lógicas que en el mundo cotidiano parecen lo único real, que lo activa llevándolo al límite, al umbral, a «la diferencia misma entre estar fuera y dentro» ${ }^{37}$.

Alejandro Rojas Jiménez es Profesor de filosofía en la Universidad de Málaga, y presidente de la asociación para la promoción de la filosofía y la cultura en Málaga

(FICUM).

Lineas de investigación:

Heidegger, Schelling, Idealismo alemán, Platón, corrientes hermenéuticas contemporáneas

Publicaciones recientes:

«Indicación de la situación hermenéutica que envuelve a la filosofía platónica», Anales del seminario de historia de la filosofía 32/2 (2015),

315-343.

«Von der Unheimlichkeit und der Auffassung der Welt in der

Spätphilosophie Heideggers» Fenomenologia. Pismo Polskiego Towarzystwa

Fenomenologicznego 13 (2015), 143-154

«De Kant a Fichte», Claridades 8 (2016), 105-125.

Email: rojas_a@uma.es

37 Leyte, A, «Figuras constructivas del paisaje», Sileno: Variaciones sobre arte y pensamiento, 11 (2001), p. 17. 
